ORIGINAL ARTICLE

\title{
High prevalence of jumper's knee and sonographic changes in Swedish elite junior volleyball players compared to matched controls
}

\author{
K Gisslèn, C Gyulai, K Söderman, H Alfredson
}

Br J Sports Med 2005;39:298-301. doi: 10.1136/bjsm.2004.014290

Background: Jumper's knee is a common and troublesome condition among senior volleyball players, but its prevalence among elite junior players compared to matched non-sports active controls is not known. Objective: To clinically, and by sonography, examine the patellar tendons in elite junior volleyball players (15-19 years) at the Swedish National Centre for volleyball and in matched controls.

Methods: The patellar tendons in the 57 students at the Swedish National Centre for high school volleyball and in 55 age, height, and weight matched not regularly sports active controls were evaluated clinically and by grey scale ultrasonography (US) and power Doppler (PD) sonography.

See end of article for authors' affiliations ......................

Correspondence to: Dr Hakan Alfredson, Umea University, Department of Surgical and Perioperative Science, Sports Medicine Unit, Umea 901 87, Sweden hakan.alfredson@idrott. umu.se

Accepted 22 August 2004
Results: There were no significant differences in mean age, height, and weight between the volleyball players and the controls. In the volleyball group, jumper's knee was diagnosed clinically and by US in 12 patellar tendons (10 male and two female). In 12/12 tendons, PD sonography demonstrated a neovascularisation in the area with structural tendon changes. In another 10 pain free tendons, there were structural tendon changes and neovessels. In the control group, no individual had a clinical diagnosis of jumper's knee. US demonstrated structural tendon changes in 11 tendons, but there was no neovascularisation on PD sonography.

Conclusions: A clinical diagnosis of jumper's knee, together with structural tendon changes and neovascularisation visualised with sonography, was seen among Swedish elite junior volleyball players but not in matched not regularly sports active controls. Structural tendon change alone was seen in $10 \%$ of the control tendons.
J umper's knee (chronic patellar tendinosis) is a troublesome condition characterised by activity related pain and/ or soreness at the patellar tendon insertion into the patella. ${ }^{1-4}$ The aetiology and pathogenesis are unknown, but an association with overuse of the knee joint extensor mechanism is suggested as the main causative factor. ${ }^{235-8}$ In sports such as volleyball and basketball, the patellar tendon is exposed to landing forces of $8 \mathrm{kN}$ (equalling 6-8 times the body weight), compared with $0.5 \mathrm{kN}$ during walking. ${ }^{6}$ The condition is the most common overuse injury in senior volleyball $(28 \%)$, and $40 \%$ of professional players have experienced symptoms of jumper's knee during their careers. $^{9}$

Treatment of the condition is difficult and there is no treatment of choice, conservative or surgical. ${ }^{10-13}$ This emphasises the need for more studies that could help to clarify the aetiology and pathogenesis of this condition.

To our knowledge, there are no studies on the prevalence of jumper's knee in junior volleyball players, though in junior basketball players the prevalence has been shown to be $7 \%{ }^{14}$

The aim of this investigation was to calculate the prevalence of jumper's knee in Swedish elite junior volleyball players and in matched not regularly sports active controls. Clinical examination, together with grey scale ultrasonography (US) and power Doppler (PD) sonography, were used as diagnostic tools.

\section{METHODS}

\section{Subjects}

The study was approved by the Ethical Committee of the Medical Faculty at the University of Gothenburg, Sweden.

The most talented junior volleyball players in Sweden are recruited to the Swedish National Centre for high school volleyball. General physical tests and sport specific tests are undertaken at inclusion and regularly during the season. During their 3 years at the Swedish National Centre for high school volleyball, the students play and train 37 weeks/year (including $13 \mathrm{~h}$ of training plus a varying number of matches/week). Most of the volleyball players are members of the Swedish Junior National Team and participate in international tournaments. Four teams represent the high school in the Swedish Volleyball Federation leagues, from the women's top elite division to the first and second divisions for men and women.

The controls were recruited via advertisement at the high school. They were not regularly sports active (not active in organised sport) and had been recreationally active for not more than $3 \mathrm{~h} /$ week during the last 6 months before inclusion. Subjects were matched for age, height, and weight (table 1).

After permission from the Educational Board of the Swedish National Centre for volleyball and the high school, all volleyball players (29 male and 28 female) in the first, second, and third grades (15-19 years of age) participated in the study. Fifty five (27 male and 28 female) matched controls participated.

All volleyball players and controls provided written informed consent.

\section{Questionnaire and clinical examination}

Questions to the athletes included: date of birth, amount and type of training, present and former symptoms involving the patellar tendon, treatments, other knee injuries, and results of treatments. The volleyball players and the controls who

Abbreviations: PD, power Doppler; US, ultrasonography 
Table 1 Characteristics of subjects

\begin{tabular}{|c|c|c|c|c|c|c|}
\hline \multirow[b]{3}{*}{ Variable } & \multicolumn{2}{|c|}{ Year of birth 1987} & \multicolumn{2}{|c|}{ Year of birth 1986} & \multicolumn{2}{|c|}{ Year of birth 1985} \\
\hline & \multicolumn{6}{|c|}{ Male players $(n=29)$ and controls $(n=27)$} \\
\hline & $\begin{array}{l}\text { Volleyball players } \\
(\mathrm{n}=11)\end{array}$ & Controls $(n=11)$ & $\begin{array}{l}\text { Volleyball players } \\
(n=10)\end{array}$ & Controls $(n=8)$ & $\begin{array}{l}\text { Volleyball players } \\
(n=8)\end{array}$ & Controls $(n=8)$ \\
\hline \multirow{5}{*}{$\begin{array}{l}\text { Age (years) } \\
\text { Height }(\mathrm{cm}) \\
\text { Weight }(\mathrm{kg})\end{array}$} & $16.6(16.1-16.1)$ & $16.5(16.3-16.1)$ & $17.6(17.3-17.12)$ & $17.5(17.1-17.10)$ & $18.5(18.1-19.6)$ & $18.8(18.6-19.7)$ \\
\hline & $186(176-195)$ & $186(176-192)$ & $190(182-202)$ & $187(185-192)$ & $188(179-196)$ & $188(184-192)$ \\
\hline & $71.8(63-87)$ & $70.8(61-87)$ & $81.2(60.5-91.7)$ & $78.5(63-96)$ & $79.2(63.4-95)$ & $78.9(67.5-91)$ \\
\hline & \multicolumn{6}{|c|}{ Female players $(n=28)$ and controls $(n=28)$} \\
\hline & $\begin{array}{l}\text { Volleyball players } \\
(n=11)\end{array}$ & Controls $(n=11)$ & $\begin{array}{l}\text { Volleyball players } \\
(n=10)\end{array}$ & Controls $(n=10)$ & $\begin{array}{l}\text { Volleyball players } \\
(n=7)\end{array}$ & Controls $(n=7)$ \\
\hline Age (years) & $16.4(16.0-16.10)$ & $16.5(16.1-16.11)$ & $17.6(17.0-17.11)$ & $17.5(17.0-17.12)$ & $18.5(18.3-18.10)$ & $18.4(18.0-18.8)$ \\
\hline Height $(\mathrm{cm})$ & $177(163-183)$ & $177(166-183)$ & $174(166-181)$ & $172(165-177)$ & $175(174-182)$ & $175(173-179)$ \\
\hline Weight $(\mathrm{kg})$ & $68.7(60.9-78.5)$ & $68.1(58.5-84)$ & $66.4(62.5-75.8)$ & $64.0(51.9-73)$ & $66.7(60.3-76.4)$ & $66.7(59-79)$ \\
\hline
\end{tabular}

reported pain at the patellar tendon marked the area of pain on a special knee chart.

All participants underwent a clinical examination of both knees by a registered sports physiotherapist (KG). The examination included palpation of the patellar tendon, in particular its attachment to the inferior pole of the patella. Tests that aimed to reproduce the pain of patellar tendinosis included: one leg body weighted squats and drop jumps (plyometric jump) on each leg from $20 \mathrm{~cm}$ and/or $43 \mathrm{~cm}$. Clinical tests to exclude differential diagnoses were also performed.

The following diagnostic criteria for jumper's knee were used: history ( $>4$ weeks) of exercise/volleyball associated pain at the patellar tendon insertion into the inferior pole of the patella, ${ }^{1}$ tenderness to palpation, ${ }^{15}$ and pain during provocative tests of the knee extensors. ${ }^{3} 1617$

\section{Sonography}

A single experienced musculoskeletal radiologist, who was blinded to the volleyball player's and the control's clinical history, carried out all US and PD examinations (CG). The same technical equipment was used in all examinations.

\section{Grey scale ultrasonography}

US was performed using a high resolution linear array $8 \mathrm{MHz}$ ultrasound transducer (Sequoia 512, Acuson, Mountain View, CA). Longitudinal and transverse grey scale scans of the left and right patellar tendons were carried out with the patient lying supine, first with the knee in extension and then with the knees in slight flexion $\left(20^{\circ}\right)$. The thickness of the tendon was measured and structural changes (hypoechoic areas) evident in both the longitudinal and the transverse scans were recorded.

\section{Power Doppler examination}

Power Doppler sonography was used to study blood flow in the patellar tendon. As only high flows can be registered, the technique does not allow for registration of the normal circulation in the tendon because of the relatively low flow rate.

To our knowledge, there is no method to quantify blood flow in the tendon. Therefore, we used a semi-quantitative scale as follows: 0 , no flow; 1 , flow outside the tendon; 2 , one or two vessels inside the tendon; 3 , multiple vessels inside the tendon.

For analysis, only those tendons with vessels inside the tendon were considered to have a neovascularisation.

\section{Statistical methods}

SPSS 11.0 for Windows (SPSS, Chicago, IL) was used for the statistical calculations. Mean and standard deviation is used to describe continuous data, and frequency tables with categorical variables. Differences between means were calculated using Student's $t$ test for independent groups. For categorical values Fisher's exact test (SPSS exact routine) was used. Significance levels were set at $p<0.05$. All $p$ values are two tailed.

\section{RESULTS}

\section{Subject characteristics}

All 57 volleyball players, 29 males $(51 \%)$ and 28 females (49\%), studying at The Swedish National Centre for high school volleyball, and 55 matched controls, 27 males (49\%) and 28 females $(51 \%)$, participated in the study.

There were no significant differences $(\mathrm{p}<0.05)$ in mean age (17.4 $v 17.4$ years), height $(182 v 181 \mathrm{~cm})$, or weight $(73.8 v 70.8 \mathrm{~kg})$ between the volleyball players and the controls. Descriptive data on the subjects are presented in table 1 .

\section{Volleyball players}

All results are presented as number of tendons (not number of individuals).

In the volleyball group, jumper's knee was diagnosed clinically and by US and PD sonography in 12 patellar tendons ( 10 males and two females) (table 2). In another 10 pain free tendons, there were structural tendon changes together with neovessels, and in another 11 asymptomatic tendons there were structural changes alone. In 81 patellar tendons sonography was normal (table 3 ).

\section{Controls}

In the control group, no individual had a clinical diagnosis of jumper's knee. US demonstrated structural tendon changes in 11 tendons ( six males and five females), but there was no neovascularisation on PD sonography in any tendon. A total of 99 tendons were clinically and sonographically normal.

There were significantly more patellar tendons with a clinical diagnosis of jumper's knee among the volleyball players compared to the controls $(p<0.05)$. Furthermore, there were significantly more patellar tendons with a clinical diagnosis of jumper's knee together with structural tendon changes and neovascularisation among the volleyball players compared to the controls $(\mathrm{p}<0.05)$. 
Table 2 Clinical diagnoses of jumper's knee in volleyball players $(n=57$, tendons $=114$ )

\begin{tabular}{|c|c|c|c|c|c|c|}
\hline & \multicolumn{2}{|c|}{ First grade/year of birth 1987} & \multicolumn{2}{|c|}{ Second grade/year of birth 1986} & \multicolumn{2}{|c|}{ Third grade/year of birth $1985 / 84$} \\
\hline & Male $(n=22)$ & Female $(n=22)$ & Male $(n=20)$ & Female $(n=20)$ & Male $(n=16)$ & Female $(n=14)$ \\
\hline Jumper's knee & 2 & 0 & 4 & 2 & 4 & 0 \\
\hline
\end{tabular}

There was no significant difference in the number of patellar tendons with structural tendon changes alone between the volleyball players and the controls.

There were significantly more asymptomatic patellar tendons with structural tendon changes and neovascularisation among the volleyball players compared to the controls $(\mathrm{p}<0.05)$.

\section{DISCUSSION}

This study provides information about the clinical diagnosis of jumper's knee, patellar tendon structure, and neovascularisation in two matched groups of students with completely different tendon loading activity levels.

We found that $11 \%$ of the patellar tendons of Swedish elite junior volleyball players have a diagnosis of jumper's knee. This is higher than the $7 \%$ Cook et al reported in a group of male and female basketball players (14-18 years of age), ${ }^{14}$ but lower than the $36 \%$ reported by Lian et al in a group of 47 male senior professional volleyball players. ${ }^{18}$

In our matched control group consisting of individuals not regularly active, no tendons were diagnosed with jumper's knee.

Most volleyball players are relatively tall and heavy and, therefore, it is important to match controls according to age, height, and weight. As height and weight can differ substantially in students of different age groups, in the current study controls were matched individually for the first, second, and third grades, respectively.

The diagnosis of jumper's knee based on clinical examination alone is unreliable. ${ }^{15}$ However, the combination of clinical findings together with sonographic findings, such as a widened tendon with hypoechoic areas and neovascularisation, seems to strengthen the diagnosis. US is a good method to verify structural changes in the tendon, ${ }^{19} 20$ and power and colour Doppler sonography have recently been shown to be useful for studying neovascularisation in tendons. ${ }^{21-23}$ In the current study, all patients with a diagnosis of jumper's knee based on palpation and functional tests also had structural tendon changes and neovascularisation in the painful area of the tendon.

We found structural tendon changes in asymptomatic individuals in both the volleyball group and in the control group. In our study, structural tendon changes were present in a total of $33 / 114$ tendons $(29 \%)$ in the volleyball players and in $11 / 110$ tendons $(10 \%)$ among the controls. Cook et al found structural changes in 71/268 patellar tendons (26\%) in a similar group of junior basketball players. ${ }^{14}$ Fredberg and Bolvig $^{24}$ have reported structural tendon changes in $18 / 98$ patellar tendons (18\%) in an asymptomatic group of senior elite soccer players. The occurrence of structural tendon changes in asymptomatic tendons is well known, but the clinical importance of these tendon changes has not yet been clarified. However, among junior basketball players, tendons with hypoechoic areas have been shown to have a higher risk of developing symptoms of jumper's knee than tendons with a normal structure. ${ }^{25}$

Interestingly, in our study all tendons with a clinical diagnosis of jumper's knee together with structural tendon changes also had neovascularisation. The relationship between neovascularisation and pain in chronic painful Achilles tendon has recently been discussed, and a vasculoneural ingrowth has been suggested to be responsible for the pain in that condition. ${ }^{26}{ }^{27}$ However, in this study there were also 10 tendons that had structural changes and neovascularisation but were pain free. This finding is difficult to explain, but, theoretically, these tendons might be at an early stage of change and may exhibit pain symptoms later on.

Prospective studies on this group of volleyball players will have to clarify the importance of the neovascularisation in symptomatic and asymptomatic tendons. Interestingly, in a recent study using ultrasound and Doppler sonography, a single high intensity basketball match was not associated with increased vascularity in patellar tendons. ${ }^{21}$

In the current study, it was interesting to notice that almost all the painful tendons belonged to individuals in the second and third grades (10/12), where there is more and heavier weight training and more match specific training compared to the first grade. The findings of a higher prevalence of structural tendon changes in the older tertiles is in line with the report by Cook et al in a similar group of junior basketball players. ${ }^{14}$ Tendons are active and can adapt to load, but the metabolism is relatively slow compared to other tissues, such as muscle tissue. It takes more than $48 \mathrm{~h}$ after exercise before the production of type I collagen is maximised. ${ }^{28}$ With this in mind, it can be speculated whether the increase in tendon loading activity, especially in the second and third grades, might be harmful for the tendon.

A clinical diagnosis of jumper's knee together with structural changes and neovascularisation in the tendon, seems to be common among Swedish elite junior volleyball players. As this condition is difficult to treat and sometimes ends a volleyball career, strategies for prevention are

Table 3 Clinical diagnoses of jumper's knee and sonographic findings in volleyball players versus controls

\begin{tabular}{|c|c|c|c|c|c|c|c|c|}
\hline & \multicolumn{4}{|c|}{ Volleyball players' tendons $(n=114)$} & \multicolumn{4}{|c|}{ Controls' tendons $(n=110)$} \\
\hline & \multicolumn{2}{|c|}{ Symptomatic } & \multicolumn{2}{|c|}{ Asymptomatic } & \multicolumn{2}{|c|}{ Symptomatic } & \multicolumn{2}{|c|}{ Asymptomatic } \\
\hline & Male & Female & Male & Female & Male & Female & Male & Female \\
\hline Hypoechoic regions & 0 & 0 & 2 & 7 & 0 & 0 & 5 & 5 \\
\hline Hypoechoic regions and PD flow 1 & 0 & 0 & 1 & 1 & 0 & 0 & 1 & 0 \\
\hline Hypoechoic regions and PD flow 2-3 & 10 & 2 & 9 & 1 & 0 & 0 & 0 & 0 \\
\hline No ultrasound changes & 0 & 0 & 36 & 45 & 0 & 0 & 48 & 51 \\
\hline Total & 10 & 2 & 48 & 54 & 0 & 0 & 54 & 56 \\
\hline
\end{tabular}




\section{What is already known on this topic}

Jumper's knee is a common and troublesome condition among senior volleyball players, but its prevalence among elite junior players compared to matched non-sports active controls is not known.

\section{What this study adds}

A clinical diagnosis of jumper's knee, together with structural changes and neovascularisation in the patellar tendon, was often found among Swedish elite junior volleyball players, but not in matched non-sports active controls. Structural tendon changes alone were found among controls.

required. It is, therefore, very important to discover the factors related to the aetiology of this condition. Prospective studies evaluating the effects of different training methods, and the load, intensity, and volume of training in different age groups, are needed.

\section{Authors' affiliations}

K Gisslèn, K Söderman, H Alfredson, Umea University, Umea, Sweden C Gyulai, Skövde Hospital, Skövde, Sweden

Funding for the study has been achieved through the Swedish Research Council for Sports.

Competing interests: none declared

\section{REFERENCES}

1 Blazina ME, Kerlan RK, Jobe FW, et al. Jumper's knee. Orthop Clin North Am 1973:4(3):665-78.

2 Ferretti A, Puddu G, Mariani PP, et al. The natural history of Jumper's knee. Patellar or quadriceps tendonitis. Int Orthop 1985;8(49):239-42.

3 Lian Ø, Engebretsen L, Øvrebø R, et al. Characteristics of the leg extensors in male volleyball players with Jumper's knee. Am J Sports Med 1996;24(3):380-5

4 Khan KM, Maffulli N, Coleman BD, et al. Patellar tendinopathy: some aspects of basic science and clinical management. Br I Sports Med 1998;32:346-55.

5 Kujala UM, Aalto T, Österman K, et al. The effect of volleyball playing on the extensor mechanism. Am J Sports Med 1989:10(4):295-8.

6 Richards DP, Ajemian SV, Wiley JP, et al. Knee joint dynamics predict patellar tendinitis in elite volleyball players. Am J Sports Med 1996;24(5):676-83.

7 Curwin KS, Stanish WD. Tendinitis: its etiology and treatment. Lexington, MA: Collamore Press, 1984.
8 Roels J, Martens M, Mulier JC, et al. Patellar tendinitis (Jumper's knee) Am J Sports Med 1978;6(6):362-8.

9 Ferretti A. Epidemiology of Jumper's knee. Sports Med 1986;3:289-95.

10 Cook JL, Khan KM, Harcourt PR, et al. A cross sectional study of 100 athletes with Jumper's knee managed conservatively and surgically. Br J Sports Med 1997;31:332-6.

11 Cook JL. What is the appropriate treatment for patellar tendinopathy? Br J Sports Med 2001;35(5):291-4.

12 Kettunen JA, Kvist MK, Alanen E, et al. Long-term prognosis for Jumper's knee in male athletes: a prospective follow-up study. Am J Sports Med 2002;30(5):689-92.

13 Coleman BD, Khan KM, Maffulli N, et al. Studies of surgical outcome after patellar tendinopathy: clinical significance of methodological deficiencies and guidelines for future studies. Scand J Med Sci Sports 2000;10:2-11.

14 Cook JL, Khan KM, Kiss ZS, et al. Patellar tendinopathy in junior basketball players: a controlled clinical and ultrasonographic study of 268 patellar tendons in players aged 14-18 years. Scand J Med Sci Sports 2000; 10:216-20.

15 Cook JL, Khan KM, Kiss ZS, et al. Reproducibility and clinical utility of tendon palpation to detect patellar tendinopathy in young basketball players. Br J Sports Med 2001;35:65-9.

16 Stanish WD, Rubinovich RM, Curwin S. Eccentric exercise in chronic tendinitis. Clin Orthop 1986;208:65-8.

17 Bobbert MF, Huijing PA, Van Ingen Schnau GJ. Drop jumping. II. The influence of dropping height on the biomechanics of drop jumping. Med Sci Sports Exerc 1987; 19(4):339-46.

18 Lian Ø, Holen KJ, Engebretsen L, et al. Relationship between symptoms of Jumper' knee and the ultrasound characteristics of the patellar tendon among high level male volleyball players. Scand J Med Sci Sports 1996;6:291-6.

19 Paavola M, Paakkala T, Kannus P, et al. Ultrasonography in the differential diagnosis of Achilles tendon injuries and related disorders. Acta Radiol 1998;39:612-9.

20 Åström M, Gentz CF, Nilsson P, et al. Imaging in chronic Achilles tendinopathy: a comparison of ultrasonography, magnetic resonance imaging and surgical findings in 27 histologically verified cases. Skeletal Radiol 1996;25:615-20.

21 Terslev L, Qvistgaard E, Torp-Pedersen S, et al. Ultrasound and power Doppler findings in Jumper's knee-preliminary observations. Eur J Ultrasound 2001;13:183-9.

22 Weinberg EP, Adams MJ, Hollenberg GM. Color Doppler sonography of patellar tendinosis. AJR 1998;171(3):743-4.

23 Öberg L, Lorentzon R, Alfredson H. Neovascularisation in Achilles tendons with painful tendinosis but not in normal tendons: an ultrasonographic investigation. Knee Surg Sports Traumatol Arthrosc 2001;9:233-8.

24 Fredberg U, Bolvig L. Significance of ultrasonographically detected asymptomatic tendinosis in the patellar and achilles tendons of elite soccer players. Am J Sports Med 2002;30(4):488-91.

25 Cook JL, Khan KM, Kiss ZS, et al. Prospective imaging study of asymptomatic patellar tendinopathy in elite junior basketball players. J Ultrasound Med 2000;19:473-9.

26 Alfredson $\mathrm{H}$, Öberg L, Forsgren S. Is vasculo-neural ingrowth the cause of pain in Achilles tendinosis? An investigation using ultrasonography and colour Doppler, immunohistochemistry, and diagnostic injections. Knee Surg Sports Traumatol Arthrosc 2003;11:334-8.

27 Öberg L, Alfredson H. Sclerosing therapy in chronic Achilles tendon insertional pain - results of a pilot study. Knee Surg Sports Traumatol Arthrosc 2003; 11:339-43.

28 Langberg H, Skovgaard D, Petersen $\sqcup$, et al. Type I collagen synthesis and degradation in peritendinous tissue after exercise determined by microdialysis in humans. J Physiol 1999;521:299-306. 